\title{
PROF. DR. ASLAN GÜNDÜZ
}

\section{Haluk KABAALİOĞLU*}

Kendisine çok ihtiyaç duyulan bir dönemde değerli bir hukukçumuzu kaybettik. Her türlü imkânsızlıkları, çalışma azmi ve kararlılığı ile aşarak uluslar arası düzeyde yayınlarıyla büyük bir saygınlık kazanan ve Türkiye'nin ulusal çıkarları konusunda gösterdiği duyarlılık ve ülkesine hizmet aşkıyla yanan Prof. Dr. Aslan Gündüz'ün 54 yaşında vefatı büyük üzüntü yaratt1.

1970'li y1lların sonunda rahmetli hocamız Profesör Mahmut Belik, beni yeni asistanı Aslan Gündüz ile tanıştırdı. Ben 1972 yılında birkaç ay İÜHF de Profesör Belik'in yanında asistanlık yapmış ancak daha sonra yurt dışında bir burs bulduğum için ayrılmak zorunda kalmıştım. Prof. Mahmut Belik ile dostluğumuz uzun ylllar sürdü ve genellikle beni öğle saatlerinde Elmadağ Divan pastanesinde yarımay çörekle çay içmeye davet ederdi. Belik Hoca beni Aslan Gündüz ile orada tanışırı. Oldukça asık yüzlü bir kişi izlenimi vermişti. Ancak Mahmut Bey, yeni asistanına yardımcı olmamı istediği için zaman zaman doktora tezi konusunda görüşüyorduk. Ben de katıldığım bir seminerde gerek ABD ve gerekse İngiltere'de Devletin yarg1 muafiyeti konusunda çıan yasalardan esinlenerek tezimi bu konuda yazmayı düşünüyordum. Epey de kaynak toplamıştım. Ancak baktım ki Aslan da aynı konuda çalışmak istemektedir. Elimdekileri ona vererek ben başka konuya eğildim. "Doktora tezi konumu çaldın" diye kendisine hep takılırdım. Aslan Gündüz'ün yayınladığı ilk kitap doktora tezi idi: Yabancı Devletlerin Yargı Bağışıklığı ve Milletlerarası Hukuk, Istanbul, 1984-Ü̧̧dal Neşriyat, (399 sahife).

Orta ve yüksek öğrenimini yaparken Devlet Demir Yollarında çalışan Gündüz, son derece zor koşullarda kendini yetiştirmişti. Aslan Gündüz yabancı dil konusunda kendi kendine çalışmış ve İngilizceyi süratle öğrenmişti. İki yıl sonra, İngilizce yazdığı bir makaleyi bana okutturmak

\footnotetext{
* Prof. Dr., Marmara Üniversitesi Avrupa Topluluğu Enstitüsü Kurucu Müdürü
} 
istedi. Hiç unutmam Üsküdar sahilinden Beylerbeyi'ne doğru yürüdük. Deniz kenarına yakın bir yerde yazdığ makalede düzeltmeler yapmak için oturduğumda Aslan'in kısa sürede yabancı dilini geliştirdiğini gördüm. Makalesini güzel bir İngilizce ile kaleme almıştı. Düzeltilecek bir hata yoktu. Tabii Mahmut Belik Hocanın ilk günlerde asık yüzlü bulduğum asistanının gerçekten de son derece güçlü bir kişiliğe sahip olduğunu ve azmederek bir çok güçlüğü aşabilen bir karakterde aslında son derece güler yüzlü olduğunu o gün daha iyi anlamıştım.

Lahey'deki Barış sarayında faaliyet gösteren Devletler Hukuku Akademisi yöneticileri önerdiğim kişilere burs verilmesini sağlıyorlardı. 1980 y1lında Lahey Devletler Hukuku Akademisinde Aslan Gündüz'e doktora bursu verildi. Tez çalışmalarını hemen hemen bitirmişti ama son çıkan yayınlardan yararlanarak bazı ekler yapabilmesi olanağı tanıyan bu bursla Aslan Lahey'e gitti. Ben ise Akademinin Uluslararası İlişkiler ve Uluslararası Hukuk Merkezinin bir aylık bir programına katılıyordum. Fransızca çalışma grubuna da hocam Köksal Bayraktar katıldı. Köksal Bayraktar Hocam ve Aslan Gündüz ile birlikte 1980 yılında Lahey'den güzel anılarımız oldu.

Aslan Gündüz IÜHHF de göreve devam ederken ben de Marmara Üniversitesi'ne girmiştim. Marmara Hukuk fakültesi açılınca tabii Aslan'a rahat vermiyor ve kendisinin Marmara'ya geçmesini istiyordum. O tarihte karşı yakada oturmalarına rağmen Marmara Hukuk'a geçmeyi kabul etti.

Şimdi Yeditepe Üniversitesi Rektörü olan Prof. Dr. Ahmet Serpil 1985 yılında Marmara Üniversitesinde yüksek lisans düzeyinde kurduğu "Çağdaş İşletmecilik Programı"na beni müdür olarak atadı. Dersler, Teşvikiye'de ünlü Tozan köşkünde yapıllyordu. Tabii ben müdür olduktan sonra yardımcım olarak Aslan Gündüz’ü aldım. Programın büyük bir ciddiyetle yürütülmesinde ve yerleşmesinde Aslan'ın büyük katkıları olmuştu.

Ben 1984-85 döneminde Virginia Üniversitesi Hukuk Fakültesinde Fulbright profesörii olarak bulunurken Prof. John Norton Moore'un başkanı olduğu Deniz Hukuku Araştırma Merkezi faaliyetlerini takip ediyordum. Aslan da ülkemizin deniz hukuku sorunlarını yakınen izliyordu. Bu nedenle Aslan'ın Virginia Üniversitesine gitmesini önerdim. Evli ve iki çocuk babası olan Aslan, bilimsel çalışmalar için hiçbir özveriden kaçınmıyordu. Öğretmen olan eşi de kendisini destekliyor ve Aslan Gündüz'ün bilim dünyasında yükselmesi için gerektiğinde kimselerin yapmayacağı fedakarlıkları yapıyordu. Bir yıl süreyle Charlottesville, Virginia'da özellikle kıt'a sahanlığı konusunda yoğun çalışmalar yaptı. Türkiye'nin en önemli meselelinedn biri olan kit'a sahanlığ konusunda doçentlik 
çalşmalarını derinleștiren Aslan Gündüz, daha sonra bu konuda değerli bir eser de yayinladı: The Concept of the Continental Shelf in Its Historical Evolution (With Special Emphasis on Entitlement), Marmara Üniversitesi, AT Enstitüsü Yayını, İstanbul, 1990 (260 sahife). Bana da düşen o tarihlerde kitabı Paris'de, Lahey'de ünlü kitapçılara götürerek raflara konmasını sağlamak oldu. Tabii burada esas amaç kitabın konuyla ilgili kişilerin eline geçmesi idi. $O$ nedenle kitapçıdan para alınmıyor uygun göreceği başka eserleri göndermesi öneriliyordu.

Ayrıca Aslan Gündüz 1980 ve 1989 yıllarında Birleşmiş milletler milletlerarası Hukuk Komisyonu bursu ile Cenevre'de Komisyonun çalışmalarını izledi, araştırmalar yaptı.

Türkiye'nin milli meselelerine büyük bir duyarlılıkla yaklaşan Aslan Gündüz, Limni adasının silahlandınlması konusunun gündeme geldiği günlerde bu konuda da bir kitap yayınladı: Limni Adası'nın Hukuki Statüsü Üzerinde Türk Yunan Uyuşmazlığı, Istanbul, 1985- Otağ Yayınevi (120 sahife). Aynı yıl "İki Taraflı ve Çok Tarafl Milletlerarası Antlaşmaların Işı̆̆ında Bulgaristan Türklerinin Durumu"nu inceleyen makalesi de ilgi çekti.

İlk baskısını 1986 ve ikinci baskısını 1994 yılında gerçekleştirdiği Milletlerarası Hukuk ve Milletlerarası Teşkilatlar Hakkında Temel Metinler kitabı daha sonra da yeni baskılar yaptı. Rahatsızlığı sırasında bu kitabın yeni baskısını tamamlayamamaktan yakınıyordu. Temennim meslektaşlarının bu kitabı yenileyerek Aslan'ın eserini devam ettirmeleridir.

1984 yılında Türkiye'de Bruges'daki "College of Europe" benzeri bir Avrupa Koleji kurulması için kırka yakın maddesi olan bir yasa tasarısı hazırlamış ve rektörümüz sayın Prof. Dr. Orhan Oğuz aracılığıyla ilgililere sunmuştuk. Unutulan bu tasarı, 14 Nisan 1987 de Türkiye AT ye tam üyelik başvurusu yaptığında hatırlandı ve iki ay sonra 18.06.1987 de ilgili yasalara tek bir cümle eklenerek, Marmara Üniversitesi Rektörlüğüne bağlı olarak bir "Avrupa Topluluğu Enstitüsü" kurulması kararlaştırıldı. Prof. Dr. Orhan Oğuz Hocamız Göztepe kampüsünde lojman olarak kullanılan binada bize bir daire tahsis etti ve hemen Eylül ayında eğitime başladık. Ne var ki Aslan $\mathrm{ABD}$ de idi ve o nedenle birinci yıl Enstitui müdür yardımcısı atamak istemedim ve Aslan'1 bekledim. Ancak ertesi yıl yurda dönüşünde Aslan yine yardımcım olarak 1988 de Enstitüde göreve başladı. İngiltere'de AB Hukuku konusunda öncü bir isim olan Prof. Dominik Lasok da bize katıldı ve sekiz yıl $A B$ Hukuku dersleri verdi.Enstitüdeki yüksek lisans yapmakta olan ögrencileri AB kurumlarını yakından tanımak ve yöneticileriyle tanışmalarını sağlamak için Brüksel, Lüksembourg ve Strasbourg'a 
götürüyorduk. İki hafta süren ilk gezide öğrencileri ben götürmüştüm. İkinci yıl gerekli kişilerle tanışması ve bu kurumlara aşinalık kazanması için Aslan ile birlikte gittik. Brüksel'de NATO'ya, Avrupa Komisyonunun çeşitli Genel Müdürlüklerine, Lüksembourg'da AT Adalet Divanı'na, Avrupa Yatırım Bankası ve İstatistik Ofisine, Strasbourg'da Avrupa Parlamentosu'na, Avrupa Konseyi Hukuk İşleri Genel Müdürlüğü, AİHM ne ziyaretler yapılır öğrenciler yetkililere sorular sorar, tez konularına ilişkin araştırma yaparlardı. Avrupa Parlamentosunda Türkiye ile ilgilenen dört beş parlamenter bir araya gelerek öğrencilerimize Avrupa ve Türkiye konularında konuşmalar yaparlar, öğrenciler de bir yıl yoğun bir şekilde $\mathrm{AB}$ konularını çalıştıklarından parlamenterlere duman attırır, yanlış ve önyargılı yaklaşımlanı şiddetle eleştirir, karşı tarafı etkilerlerdi. Profesör Aslan Gündüz ile Enstitüde amacımız kişilik sahibi, ülke çıkarlarını savunan, yabancıların her söylediklerini keramet gibi kabul etmeyen, sorgulayan mücadeleci gençler yetişmesini sağlamaktı. Zaten AP parlamenterleri diplomatlardan veya profesörlerden değil de birkaç yabanc1 dili konuşan genç üniversite öğrencilerinden aldıkları mesajlardan daha çok etkileniyorlard1. AP Başkanı Lord Plumb dahi öğrencilerimizi kabul ediyor, uzun görüşmeler yapıyorlardı. Daha sonraki yıllarda bu gezilere öğrencileri Aslan Gündüz götürdui. Aslan, vakur, şahsiyetli yaklaşımı ve konulara hakimiyeti ile uluslar arası temaslarda ögrencilerimize de güzel örnek oluyordu. Şimdilerde AB kurumlarından gelen alt düzey memurlar veya yabancı uzmanlara hoş görünmek için ne yapacaklarını şaşıran kişileri gördükçe Aslan Gündüz'ü çok ama çok arayacağımızı düşünüyorum.

Ekim 1994 de profesörlük başvurusuna ek olarak sünduğu yayın listesinde be kitap, on altı makale, ùç tebliğ yer alıyordu. Doktora tezine sekiz ayrı bilimsel çalışmada atıf yapılmıştı. Daha o tarihte sekiz yüksek lisans ve iki doktora tezinde danışmanlık yapmıştı. Milletlerarası Hukuk ve Milletlerarası Özel Hukuk Bülteninde çok sayıda makalesi yayınlandı. Deniz Kuvvetleri Komutanlığı Deniz Hukuk Sempozyumlarına 1988 den itibaren katıldı. O y1l "Deniz Savaş Hukukunda Tarafsızlık Kavramı ve IrakIran Savaşında Tarafsiz. Devletlerin Ticaret Gemilerine Yaptlan Muamelenin Hukukiliği" konulu bir tebliğ sunmuştu. Bir önemli makalesi de 1990 yılında İstanbul Barosu Dergisinin 1-3 sayısında yayınladı: "Iktidar ve Milletlerarast Sinirlart" (s. 14-64) . Prof. Mahmut R. Belik Armağan'ında yayınlanan iki makalesi de toplam 175 sahife kadardı. Aslan Gündüz'ün profesörlük jürisi üyesi olarak vurguladığım bir başka husus da yedek subaylığını Genel Kurmay Başkanlığı Antlaşmalar Dairesinde yapmış olmasının kendisine önemli deneyim kazandırmış olması idi. Gerçekten de "kendi anabilim dalı ile ilgili bir çok antlaşmanın hazırlanması ve tatbiki 
evrelerinde hukuki görüş bildirmesi bilimsel çalışmalan açısından önemli bir tecrübe kazanmasına yol açmıştı."

1994 yılında Bükreş'de yapılan bir uluslar arası sempozyumda "World Project on the Freedom of Religion: the Turkish case" konulu elli sayfalık raporu önemli bir başka çalışmasıydı. Daha sonra da çok sayıda makale ve eser veren Aslan Gündüz, vefatından birkaç ay önce evinde ziyaret ettiğimde Amerika'da yayınlanan bir kitapda kendi makalesine de yer verildiğini belirterek o eseri gösterdi. Yaklaşık otuz yıl önce Beylerbeyi sahilinde yazdığı İngilizce makalesini okumamı isteyen Aslan Gündüz Fransızcayı da öğrenmiş ve sadece ülkemizde değil yurt dışında da bilimsel çalışmalara önemli katkılar sağlıyordu.

1992 y1lında Türkiye'nin insan hakları sorunlanı Avrupa'nın gündemine getiriliyordu. Öğrencilerin yüksek lisans ve doktora çalışmalan için verilen Jean Monnet burslarından birine, kendisine haber vermeden Aslan'1 aday gösterdim. Kabul etmek istemedi ise de insan hakları konusunda daha derinlemesine ihtisaslaşmamız gerektiğini ve bu konuda kendisinin öncülük etmesini rica ettiğimi söyledim. Beni kırmadı ve bir yıl süreyle Essex'de öğrenci yurdunda kalmak suretiyle oradaki insan hakları programını başarıyla bitirdi. Burs çok kısıtlı bir ödeme öngördüğünden küçük bir odada kaldı ancak önemli eserlere imza attı. Kendisi kıdemli bir doçent olmasına rağmen-YÖK bursuyla giden öğrencilere yapılan ödemenin yarısı kadar bir bursla yetindi. Yapılan ödemeyle bir öğrencinin ancak kişisel harcamaları karşılanabildiğinden ailesi yine İstanbul'da kalmıştı. Yazın bir ay şimdi doktor olan oğlu yanına gelmiş ve o küçük odayı paylaşmışlardı. Aslan Gündüz ve ailesi bu fedakarlığı yaptı. Bilimsel alanda mükemmelliğe ulaşmak için her türlü özveriyi göze aldığını gösterdi ama Türkiye'nin en iyi insan hakları hukukçusu oldu.

Aslan Türkiye'ye döndügüünde tüm eserlerini bir zarfa koyup Dışişleri Bakanlı̆̆ı Müsteşarı Büyükelçi Özdem Sanberk'e gönderdim. Strasbourg'daki davalarda Aslan Gündüz'den mutlaka yararlanılmalıydı. Müsteşara Aslan Gündüz'ün Türkiye'nin ulusal çıkarlarının korunmasında fevkalade hassas, son derece güvenilir ve dirayetli bir hukuk adamı olduğunu yazdım. Kısa bir süre sonra Aslan Türkiye'nin Strasbourg'daki avukatlarından biri oldu. Hem de bir çok davayı kazanarak kaybedilen davalar dizisinde şeytanın bacağını kırdı. PKK davalarında Diyarbakır'da şahit dinlenirken yalan söyleyen, vereceği ifade kendisine ezberlettirilen tanıklara birkaç soru sorarak gerçekleri çarpıttıklarını ortaya çıkaran Aslan, gerçekten de çok önemli bir çok davayı büyük başarıyla kazandı. Orada kendisine terör örgütü mensubu olduğunu iddia eden kişilerce yöneltilen 
tehditlere pabuç bırakmadı. Karşısında aslında büyük mali imkanları olan çok sayıda avukatın çalıştığı ve amaçları Türkiye'yi sıkıştırmak olan güçlü bir hukukçular grubu vardı. Hedefleri insan haklarını korumak değil terör örgütünün iddialarına destek olarak Türkiye'yi zor durumda bırakmaktı. Dost ve müttefik sandığımız ülkeler bazı sözde sivil toplum örgütleri kanalıyla bu kişilere büyük meblağlar transfer ettiler. İngiltere'de bir üniversitede Profesör Kevin Boyle'ün yönetimindeki bir grup İngiliz hukukçu ve avukat, PKK davalarını tezgahlamakta ve ülkemizin mahkum olmasına yola açmaktaydı. Bu hukukçular grubuna büyük fonlar sağlanmış. Türkiye'yi Strasbourg'da köşeye sıkıştırabilmek için kendilerine binlerce sterlinlik ödeme yapılıyordu. Bizim Aslan ise Dışişlerinin ayda verdiği 33 milyon TL ile dosyalar konusunda görüşmek için her ay hem Ankara'ya gidiyor, hem Strasbourg'da davaları savunuyor, hem de şahit dinleme, mahallinde keşif yapmak gibi nedenlerle Güneydoğuya gidiyordu. Ödenen meblağ masraflarını dahi karşılamaktan uzaktı.

KKTC seçimlerinden önce 59. Hükümetin Loizidou kararını kabul edip tazminatı ödeyeceğini açıklaması, Çapa Tıp Fakültesi hastanesinde ziyaret ettiğim Aslan'ı ve eşi Kezban Hanımı fevkalade üzmüştü. Bu yapılacak bir şey değildi. Türkiye'nin başına çok sorun açabilirdi. Ancak bu karar, sanki KKTC seçimlerinde muhalefetin kazanmasını da sağlamak üzere tam seçimlerden önce alınmıştı. (Gerçekten de KKTC de bazı siyasi partiler TC Hükümetinin bu kararını çok güzel istismar ettiler ve siyasi gözlemcilere göre bu karar sayesinde oy oranlarını üç dört puan arttırdılar.) Halbuki Aslan, Avrupa İnsan Hakları Mahkemesinin kararındaki yanlışları, çelişkileri, önceki ve sonraki içtihatlarda çok farklı kararlar veren AİHM nin Türkiye'ye yaptığı haksızlıkları, "Perceptions" isimli dergide aynntılarıyla yazmıştı: "Creeping Jurisdiction of the European Court of Human Rights: The Bankovich Case vs. the Loizidou Case"Sept-Nov 2002 (vol.VII). Bir çok uluslar arası hukuk uzmanı AİHM nin yanlış karar verdiğini ve bundan dönmek istediğini belirtiyordu. Hatta daha sonra Yugoslavya olaylarına ilişkin davalarda Divan tam tersi kararlar vermişti. Ancak son zamanlarda moda, en haklı olduğumuz konularda dahi sürekli olarak Türkiye'nin ulusal politikalarını eleştirmek idi. Hastanede yatağından televizyon tartışmaları izleyen Aslan kahroluyordu. Bu kadar yanlış ve haksız bir kararı malum çevrelerin nasıl dillerine pelesenk ettiklerini gördükçe üzüntüsü daha da artıyordu. Bazı emekli diplomatlar, bazı köşe yazarları, televizyonun malum programciları, ordan burdan "proje alıp para kazanmak sevdasına düşen" sözde bilim adamları, sözde sivil toplum örgütleri, birilerine yaranmak için makbul yaklaşımın kendi ülkelerine saldırmak olduğunu düşünüp, gerçekleri tahrif ediyorlardı. Ülke çıkarlarına olağanüstü duyarlılıkla sahip 
çıkan Aslan Gündüz, hasta yatağında ne kadar kahrolduğunu anlatırken aslında çıkıp bu şahıslara cevap verememenin üzüntüsü içinde idi.

Maltepe Camiinde cenazesi kalkmadan önce eşi Kezban Hanım, Aslan'ın tabutunun Türk bayrağına sarılmasını haklı olarak istiyordu. Hemen büyük bir bayrak temin ettik ve Türk bayrağına sarılı gitmeyi en çok hak eden Aslan'ı öyle uğurladık. Nur içinde yatsın... 